\title{
Financiamiento
}




\section{Las Pyme y el desarrollo}

Guillermo Barcelli G.

Ingeniero mecánico electricista por la Universidad Nacional de Ingenieria. Maestria en Banca y Finanzas por la Universidad de Lima. Especialista en administración de la producción industrial en Carl Duisberg Gesellschaft e.v. y asociaciones industriales de los paises del Pacto Andino (Bonn, Alemania). Superintendente de mantenimiento de la fábrica Textil El Amazonas.

En el presente artículo se evidencia la importancia que tienen las Pyme en el mercado nacional y en las economías en desarrollo. Se entiende que las Pyme nacionales tienen una tecnología atrasada que no permite su competencia al mismo nivel que las de los paises que nos exportan sus productos, por lo que se promueve el apoyo a la industria que demuestre voluntad de cambio, para que en un futuro se vean convertidas las Pyme peruanas en medianas o grandes empresas, con un nivel competitivo sistemático y una cultura industrial suficientemente sólida como para no cerrarlas. 
Pyme (Pequeña y Mediana Empresa), uno de los acrónimos más utilizados en los últimos tiempos, ha sido popularizado gracias a la infinidad de medios de comunicación que lo utilizan en forma cotidiana. Todos saben que las Pyme son las que consumen la mayor parte de la cooperación internacional; es público y notorio el apoyo que les da o les pretende dar el Gobierno; ministerios e instituciones gremiales han creado sectores y comités ad hoc liderados por connotados especialistas, que cuentan con la importante asistencia de experimentados profesionales; la mayoría de las ONG se han especializado en el trabajo con las Pyme y están dedicadas a hacerles llegar una importante cantidad de recursos donados por los países desarrollados, los cuales dan prioridad al apoyo a este sector.

No es necesaria mayor abundancia de razones para dejar establecido que todos le han adjudicado una inmensa importancia a las Pyme, dando incluso la impresión de que una muy buena parte del futuro de nuestro país descansa pesada y esperanzadamente en ellas. Se percibe claramente que las Pyme son la punta de lanza de nuestro plan de desarrollo, de esta manera se les ha delegado una enorme responsabilidad que podría ser mayor que sus capacidades.

Sin negar la evidente importancia que tienen las Pyme dentro de la economía nacional, y en las economías de los países en desarrollo, cabe hacer algunas reflexiones.

En el actual entorno de dura competencia, frente a mercados globalizados que nos obligan a competir tanto con las empresas vecinas como con las que estando localizadas en países lejanos y exóticos, amenazan con quitarnos la exigua y disminuida clientela que nos queda; con una economía de libre mercado que llevada a sus extremos exagera y deviene en un liberalismo a veces muy duro para nuestras actuales condiciones técnicas, económicas, financieras, y hasta éticas; resulta realmente riesgoso esperar que nuestro sector de la pequeña empresa obtenga buenos resultados, parece que no se debería apostar al logro de un desarrollo nacional basado en gran medida en el impulso de las Pyme.

Hasta donde conocemos de las Pyme nacionales -y si bien es cierto que no es mucho lo que conocemos- hemos podido apreciar que tienen una tecnología atrasada que les dificulta una producción competitiva, que no están bien organizadas despilfarrando muchas veces los escasos recursos que poseen, que no tienen una gestión moderna que les garantice la obten- 
ción de los resultados planificados estratégicamente, y que no actúan en un escenario propicio, con las condiciones marco que propugna la competitividad sistémica. Estas observaciones empíricas parecen explicar las razones principales para que las Pyme no puedan alcanzar los niveles de calidad, productividad y oportunidad o servicio necesarios para competir exitosamente en el entorno actual, dando como resultado que en nuestras tiendas estemos casi obligados a comprar galletas argentinas, cocinas brasileñas, aceite boliviano, café chileno, sardinas ecuatorianas, chocolates colombianos, atún venezolano, confecciones tailandesas, telas chinas, muebles malayos, zapatos rumanos, válvulas italianas y electrodomésticos coreanos. Sin ninguna mala intención en contra de los países que nos exportan sus productos, cabría preguntarnos si teniendo una balanza comercial cada vez más negativa con ellos podremos pretender el desarrollo que nos permita una mejor calidad de vida.

Entendemos que la única manera de revertir esta situación -de lograr capacidades competitivas a nivel internacional, que es el nivel que cuenta- sería invertir en la capacitación que permita mejorar la organización y la gestión, seleccionar y emplear eficaz y eficientemente la tecnología; elevar el nivel tecnológico nacional a los niveles internacionales; crear una cultura industrial de primer orden. No conocemos ninguna región o país que haya alcanzado el desarrollo, elevando su calidad de vida, sin haber logrado antes una industria competitiva internacionalmente. El desarrollo económico pasa por el desarrollo industrial.

Sabemos que las Pyme han tenido éxito en muchos países, pero siempre como competitivas y cautivas proveedoras de las megaempresas transnacionales, o consiguiendo nichos de mercado merced a una inversión y esfuerzo de mercadotecnia y de investigación y desarrollo. Es decir, estas Pyme alcanzan y sostienen el nivel competitivo de sus clientes o cierran desplazadas por otras Pyme que son capaces de producir con más calidad, mejor productividad, o en forma más oportuna; es decir, son Pyme con una tecnología, una organización y una gestión que envidiarían algunas empresas grandes de los países en vías de desarrollo, que no están en condiciones o no se atreven a apostar ni siquiera por la tecnología de lo obvio, nuestras Pyme no son otra cosa que medianos o grandes talleres artesanales.

Aún carecemos de una cultura industrial. Estamos convencidos de que el liberalismo debe ser adecuadamente gerenciado 
en favor del país, creemos en la competitividad sistémica. Por lo tanto propiciamos que se apoye a la industria viable, a la que muestre -y sobre todo demuestre- voluntad de cambio. Conocemos algunas Pyme que en 1973 estaban mejor o igual que ahora, en las que no ha habido avance tecnológico, donde la organización llega actualmente a niveles caóticos y la gestión no toma decisiones adecuadas y está atada de manos por culpa del nepotismo.

Lo más interesante es que los propietarios y administradores de estas empresas han sido y son dirigentes de las instituciones del gremio de las Pyme, especialistas que asesoran a instituciones estatales, expertos que aprendieron asistiendo a muchos congresos del sector, visitando muchas Pyme de otros países y recibiendo bastante apoyo de los organismos de cooperación internacional de los países desarrollados, que se preocupan en apoyar tanto a nuestras Pyme, que si pensáramos con mala intención diríamos que conocen perfectamente la problemática, y lo que esto significa para ellos y para nosotros en el futuro. No hay estadísticas al respecto, pero nos gustaría saber cuántas Pyme han cerrado en los últimos años, cuántas alcanzaron un nivel competitivo y cuántas llegaron exitosamente a ser medianas o grandes empresas.

Nuestras reflexiones nos llevan a plantear lo siguiente:

- La ayuda indiscriminada de las Pyme es un despilfarro

- No apoyar a las Pyme que no demuestren que lo merecen.

- Favorecer a empresas viables con voluntad real de cambio sin importar su tamaño

- Apoyar la competitividad sistémica

Nuestro propósito es llamar la atención de los interesados en el sector, e inquietar especialmente a los que deseando el desarrollo del país no aceptamos el despilfarro de atenciones y recursos tan escasos y necesitados. Deseamos que de estas elucubraciones surjan investigaciones esclarecedoras. 